Association for Information Systems AIS Electronic Library (AISeL)

PACIS 2001 Proceedings

Pacific Asia Conference on Information Systems

(PACIS)

December 2001

\title{
Exploring the Factors Enhancing Member Participation in Virtual Communities
}

Won-Seok Yoo

Accenture, Korea

Kil-Soo Suh

Accenture, Korea

Moon-Bong Lee

Yonsei University

Follow this and additional works at: http://aisel.aisnet.org/pacis2001

\section{Recommended Citation}

Yoo, Won-Seok; Suh, Kil-Soo; and Lee, Moon-Bong, "Exploring the Factors Enhancing Member Participation in Virtual Communities" (2001). PACIS 2001 Proceedings. 38.

http://aisel.aisnet.org/pacis2001/38

This material is brought to you by the Pacific Asia Conference on Information Systems (PACIS) at AIS Electronic Library (AISeL). It has been accepted for inclusion in PACIS 2001 Proceedings by an authorized administrator of AIS Electronic Library (AISeL). For more information, please contact elibrary@aisnet.org. 


\title{
Exploring the Factors Enhancing Member Participation in Virtual Communities
}

\author{
Won-Seok Yoo (Accenture, Korea) \\ Kil-Soo Suh, Moon Bong Lee \\ (Yonsei University)
}

\begin{abstract}
The purpose of this study is to find the factors that enhance member participation in business-to-customer virtual communities. Although there are many factors influencing member participation, this study limits its independent variables to those of managing strategy and information system quality. In addition to finding their direct impacts, this study identifies indirect effects through two mediating variables such as member visit and sense of community. The result of this study revealed that there was no significant direct path from managing strategy to participation. However, the path from sense of community to participation was strongly supported by the results. This then implies that a manager of a community has to emphasize the sense of community, membership in particular, in order to enhance participation. In addition, the results showed that sense of community could be enhanced by an appropriate managing strategy, while the number of visits could be increased by the information system's quality.
\end{abstract}

Keywords: Virtual community, Participation, Sense of community, Visit, Managing strategy, Information system quality

\section{Introduction}

The proliferation of the Internet has created a lot of new phenomena, some never before imagined. One such example is that of the 'virtual community'. Communities were once thought of in terms of geographical boundaries such as a township or neighborhood. Now, however, we have the concept of a virtual communities. People can interact based upon common interests and goals regardless of their location. Martin (1999) pointed out the virtual community as one of seven factors that would change the way of business in the 21 st century, while Sculley and Woods (1999) argued that the virtual community would be the key factor for the success of the B2B e-Marketplace. In fact, communities are considered to be one of the three most important factors, along with content and commerce, that compose Internet business. In the United States, 'iVillage' (http://www.ivillage.com) has a typical business model that uses virtual communities as the primary source of revenue. The site achieved, on average, 204 million monthly page views during the third quarter of 2000, and its membership 
grew to approximately 5.7 million users during the same period. Meanwhile, Daum Communication of Korea (http://café.daum.net) has 8.8 million members and 210,000 communities as of October 2000. During the year 2000, the most successful site in Korea was 'I Love School' (http://www.iloveschool.co.kr) which attracted 6 million members within a year and achieved 2 billion page views per month by October 2000 . The site succeeded by furnishing all the schools in Korea with virtual communities. In October 2000, Daum and 'I Love School' were ranked fourth and sixth respectively by Alexa (http://www.alexa.com). Kozinets (1999) estimated that by the year 2000, over 40 million people worldwide would join in at least one virtual community.

Then why is the virtual community highlighted in this Internet era? There are three explanations. For one, the virtual community could be the new market for a business, thus large numbers of companies develop this for the purpose of commerce (Hagel III and Armstrong, 1997). Second, the virtual community could be used for enhancing customer loyalty for a specific brand (Reichheld and Schefter, 2000; McWilliam, 2000). The third and most important reason is the basic human need for personal relationships (Rheingold, 1992). Whatever the explanation, the Yankee Group reports that U.S. companies invested over $\$ 300$ million in community software, implementation and management in 1999 (Meehan, 2000).

The purpose of this study is to find the factors that enhance member participation in business-to-customer(B-to-C) virtual communities ${ }^{1}$. In the beginning stages, B-to-C virtual communities were evaluated by how many members they acquired. But as more and more virtual communities arose on the Internet and people joined multiple communities, the numbers of hyper-affiliates - people who are passionate about their communities - became more important (Cothrel, 2000). Meanwhile, each community's revenue source had changed from on-line advertisement to shopping and brokerage commissions. Thus it is believed that participation should be enhanced for the community to become more successful. Although there are many factors influencing member participation, this study limits its independent variables to managing strategy and information system quality. In addition to finding their direct impacts, this study identifies indirect effects through two mediating variables such as member visit and sense of community.

\section{Prior research}

\subsection{Virtual community}

${ }^{1}$ The factors that enhance member participation in business-to-business virtual communities may be quite different from those in B-to-C. This paper only focuses on B-to-C virtual communities. 


\subsubsection{Definition}

The term 'virtual community' was first used by Howard Rheingold (1993), who defined it as a "social aggregation that emerges from the net when enough people carry on public discussion long enough, with sufficient human feeling, to form webs of personal relationship in cyberspace". However, Hagel III and Armstrong (1997) have termed it in a different way as "groups of consumers united by a common interest". And Williams and Cothrel (2000) defined it as "group of people who engage in many-to-many interactions online". The Yankee Group made a similar definition. They defined it as a large targeted audience of loyal and highly interactive users.

Taking these into consideration, it is possible to categorize the above definitions into two groups, narrow and broad. The narrow definitions include those of Rheingold and the Yankee Group, while the broad definitions include those of Hagel III and Armstrong and Williams and Cothrel. Following the narrow definition, this research identified four requirements to be a virtual community based on prior research. These requirements are commonness, interactivity, continuance, and cyberspace [Figure 1]. Commonness means the similarity in terms of interest, experience, geographic feature, or demographics. Interactivity includes two types of interactions, one between system operator (SYSOP) and member and the other between member and member. Continuance refers to those interactions that have to continue for a certain period of time. Finally, cyberspace includes all aspects of the on-line world regardless of underlying infrastructure, such as IP (Internet, Extranet, Intranet) or mobile networks.

\subsubsection{Managing strategy}

Then how does one build and operate a successful virtual community? There is little empirical research on this issue, but there are some ideas. Hagel III and Armstrong (1997) argued that people join in a virtual community to fulfill their needs for things such as information, transactions, relationships, and fantasies. Thus the virtual community should satisfy these needs through the use of content, communication, and commercialization.

Kim (2000) has focused more on the design and operation of communities by drawing on nine design principles for community-building from her own experience [Table 1]. These principles include; 'define and articulate the community's purpose', 'build flexible and extensible gathering places', 'create meaningful and evolving member profiles', 'provide a range of roles', 'promote effective leadership by developing a strong leadership program', 'define a clear-yet-flexible rule such as code of conduct and etiquette', 'organize and promote cyclic events', 'integrate a community with the real world through rituals', and 'facilitate member-created and run subgroups'.

Williams and Cothrel (2000) pointed out three keys to sustain a virtual community such as 
member development, asset management, and community relations. Member development means that communities should increase the size of their community membership and enhance member activities. Member development is important because communities need critical mass to remain active and to hold the attention of members. In addition communities have to manage assets effectively; regardless of their source. Assets to be maintained include content, alliances, knowledge, experience, and the community infrastructure (hardware, software, and interface). Finally, communities can turn visitors into participating members by strengthening their relations. For example, off-line events could help cement relationships that have been established on-line.

While Hagel III and Armstrong (1997) explain basic ideas, Kim (2000) and Williams and Cothrel (2000) show some disciplines that can be followed by the community SYSOPs, who want to create and manage virtual communities. In particular, the nine design principles of Kim (2000) cover most of the factors that were referred to by Williams and Cothrel (2000).

\subsection{Sense of community and participation}

\subsubsection{Sense of community}

Sense of community has been studied by many sociologists and psychologists since the late 1970's. Sociologists have been interested in the factors that affect the sense of community, while psychologists have been interested in the relationship between sense of community and other psychological concepts such as satisfaction and happiness (Brodsky et al., 1999).

McMillan and Chavis (1986) developed the Sense of Community Index (SCI) based on prior research. They proved the reliability and validity of this index by applying the SCI to a real-world situation (Chavis et al., 1986). This SCI is composed of four constructs: membership; influence; integration and fulfillment of needs; and shared emotional connection. Each of these constructs has their own component factors [Table 2].

The membership construct consists of the dimensions of boundary and common symbols. Narrowing the boundary of the community leads to emotional safety and an increase in membership. Common symbols such as dress, ritual, and language also increase membership.

The second construct is influence. There are two types of influences in communities. One is the influence of a community on its members and the other is the influence of members on a community. The first influence is contingent on members' cohesiveness and conformity to a community. Both could be reinforced when the community's norms and justice is consensually validated. However, the second influence is dependent on each member's nature. If a member fully understands the purpose of the community and participates in a community with a high level of leadership, he or she can increase his or her influence on the community.

The third construct is integration and fulfillment of need. Because need fulfillment is a primary function of a cohesive community, each community should make efforts to first 
identify the members' needs. The best situation is when members and their community fit each other's objectives and have shared values. However, in a given situation, a community can better fulfill the members' needs by rewarding contributing members through elevated status and privileges.

The last construct is emotional connection. It can be consolidated by quantity and quality of interactions. Thus each community has to offer shared and worthwhile events as often as possible.

\subsubsection{Participation}

Participation in a community has been considered a measurement of the community's success because it shows member satisfaction while at the same time advancing important community goals (Julian et al., 1997). A lot of research has thus focused on developing mechanisms that promote participation, such as the individual psychological benefit, sense of community, power, and involvement (Zimmerman and Rappaport, 1988).

Participation is highlighted in virtual communities as well. Community leaders must have the necessary skills to stimulate member involvement and participation as well as to attract and shepherd new members (McWilliam, 2000). Since the measurement for community success is changing from quantity measurement to quality measurement, member activity is more important than the number of members in the community (Park et al., 2000; Kozinets, 2000). Sense of community, participation, and involvement were suggested for the measurements to evaluate a community in terms of its quality (Cothrel, 2000).

\subsection{Information system quality and its use}

\subsubsection{Information system quality}

Information system quality can be divided into two aspects - system quality and information quality. System quality refers to the user's perception of the system and was first developed to measure system performance. Information quality refers simply to the quality of information generated by the system.

DeLone and McLean (1992) summarized dependent variables that had been used to measure system quality and information quality, and assumed that both are highly related with system use and its performance. These relationships were validated through later empirical research. Information quality and system quality were shown to have indirect influences on system use (Seddon, 1997; Kim and Ahn, 1998).

This relationship was applied to Internet web sites by Liu and Arnett (2000). To explore factors associated with web site success, they used information and system quality with four other factors. It was revealed that web site success was related to four major factors: quality 
of information and service, system use, playfulness and system design quality.

\subsubsection{System use}

System use is one of the most frequently reported means of measuring the success of an information system, and it reflects the attitude of the user toward the system (DeLone and McLean, 1992). While DeLone and McLean argued that information and system quality have a direct influence on system use, Seddon (1997) maintained that they had an indirect influence on it by way of usefulness and user satisfaction. In this study, system use can be viewed as a "visit" to the community.

\section{Research model}

\subsection{Research model}

Figure 2 shows the research model which seeks to examine the impact of managing strategy and information system quality on member participation in virtual communities. Since previous research (Kim, 2000; Williams and Cothrel, 2000; McWilliam, 2000) argued that appropriate managing strategy could build up cohesive virtual communities, the managing strategy may have a direct impact on member's visit, sense of community and member participation. On the other hand, information system quality is highly related with its use (Delone and McLean, 1992; Liu and Arnett, 2000). Thus, information system quality may have a direct influence only on a member's visit. However, the model also shows that managing strategy and information and system quality may affect participation indirectly through the member's visits and their sense of community.

\subsection{Research hypotheses}

\subsubsection{Managing strategy}

Many community-related articles argued that how a community is managed could determine its success (Kim, 2000; Williams and Cothrel, 2000). How to define the purpose of community, how to define and enforce its rules, how to promote events, and how to facilitate subgroups might lead a community to success in terms of member visits, sense of community, and participation. In addition, prior research about off-line communities has also showed that appropriate community operation could reinforce the members' sense of community and therefore increase their participation (McMillan and Chavis, 1986; Julian et al., 1997). This leads to the following null hypotheses: 
H1. Managing strategy has no influence on member visits.

H2. Managing strategy has no influence on members'sense of community.

H3. Managing strategy has no influence on member participation.

\subsubsection{Information and system quality}

There has been some discussion about the relationship between IS quality and its use. DeLone and McLean (1992) have argued for a direct relationship while Seddon (1997) and Davis (1986) have argued for indirect relationship. However, both agree that there is a relationship between information system quality and its use. In a recent publication on ecommerce, Liu and Arnett (2000), found that information and system quality were highly related with system use. Since system use in a virtual community may be measured in terms of the number of member visits, the following null hypothesis is proposed:

H4. Information system quality has no influence on member visits.

\subsubsection{Sense of community}

The relationship between sense of community and participation is not well understood. Many theories and past research suggest two different models: that sense of community leads to participation (Bachrach and Zautra, 1985); and, conversely, that participation leads to sense of community (Heller, 1989). The first model is particularly appealing in that planners should be able to promote participation through a mechanism that enhances the sense of community and thus improve the value of community. In fact, current research has suggested that sense of community promotes participation. In a study of neighborhood block associations, Chavis and Wanderman (1990) found empirical evidence of a causal relationship in which sense of community has a direct as well as an indirect effect on participation.

McMillan and Chavis (1986) argued that the quantity and quality of interactions between members could enhance sense of community, especially emotional connection. In addition, Park et al. (2000) revealed that there was a high relationship between the number of visits and a member's influence on a community. Thus member visits could lead to sense of community and sense of community could lead to member participation. This leads to the following hypotheses:

H5. Member visits have no influence on members'sense of community. 
H6. Members'sense of community has no influence on member participation.

\section{Research method}

\subsection{Selected communities}

To aid in generalizability, eight different communities were selected instead of one. Four were non-profit communities which were selected from community-service sites such as GeoCities, and the other four were selected among independent and profit-oriented sites such as iVillage. The most popular community-service sites in Korea are Daum (http://café.dam.net) and Freechal (http://www.freechal.com). We selected four most successful non-profit communities from these sites. Four profit-oriented community were chosen from 100hot (http://www.100hot.co.kr) that lists 100 hottest sites for every category.

To control the effect by size and operation period, the number of members was constrained to be over 2,000 for the non-profit community and over 200,000 for the profitoriented community. To provide sufficient time to establish a community, both types of communities had to have been established for at least six months.

\subsection{Procedure}

The questionnaire was designed to be completed on-line by each respondent. Since all questions were measured on a Likert 7 scale, JavaScript programming was added to the online survey to check for missing responses and to prompt the user to answer them. A pretest of the questionnaire was conducted two weeks prior to the administration of the main survey resulting in some sentences being were reworded to avoid ambiguity.

Before the survey, we contacted SYSOPs of each community and asked them to support our research by notifying their members about our research through e-mail, a message board, and an advertisement banner. To promote participation, one hundred people would receive gift certificates determined by lottery.

\subsection{Measures}

\subsubsection{Managing strategy}

After categorizing the factors that had been referred to in previous research (Kim, 2000; Williams and Cothrel, 2000), six factors of the construct managing strategy were developed. These are purpose, rule, role, event, ritual, and subgroup of virtual community. In detail, we measured the clarity of purpose, the rationality of rule and role, the frequency and quality of 
event and ritual, and the diversity of subgroup. To improve the validity and reliability of this measurement, four experts in this area verified each sentence of measure and conducted the pretest for one community.

\subsubsection{Information and system quality}

Information system quality is composed of system quality and information quality. After considering a community's features, the five measures of speed, reliability, ease of use, functionality, and recovery were developed to measure system quality from Kim and Ahn (1998)'s measures. In similar fashion, the five measures of timeliness, accuracy, abundance, customized information presentation, and useful information presentation were developed to measure information quality.

\subsubsection{Visit}

Since the concept of visit in this research is similar to system use in IS research, the means of measuring system use were applied to measure visits in a virtual community. As previously stated, visits to a community may serve as a proxy for the construct of system use. Park et al. (2000) used the frequency of visits and the average visit duration to quantitatively measure the value visit to a virtual community. Thus, member visit was measured by the frequency and time of each member's visit.

\subsubsection{Sense of community}

SCI (Chavis et al., 1986) was used to measure sense of community. Since this index was developed for off-line communities, some rewording was necessary to modify it for an on-line environment. After the modification, a pilot test was conducted to ensure that the questionnaire was clear to respondents as well as to increase the validity of the questionnaire.

Membership was measured by how many members they recognized in that community, how comfortable they were in that community, and how strongly they believed themselves to be members of that community. Influence was measured by how much they cared about what others thought of their actions, how much influence the community had on them, and how much influence they had on the community. Integration and fulfillment of needs was measured by how worthwhile the community was of their time, how well their needs were fulfilled, and how integrated their needs were with the needs of others. Emotional connection was measured by how important this community was to them, how well all members got along within that community, and how long they wanted to stay in that community. 


\subsubsection{Participation}

While 'visit' implies a low level of involvement, participation implies a high level of involvement in a community. Park et al.(1999) used two types of participation to measure member loyalty - participation in community operation and participation in communication with other members. Building on these two participation types, it is proposed that there are four aspects of participation: participation in community operation, participation in subgroup or event, participation in regular message boards, and participation in chatting or e-mail with other members. The frequency of each type of participation was used to measure participation.

\section{Data analysis}

\subsection{Data collected}

Surveys were collected over ten days with a response of 2,094 questionnaires. To ensure respondent's reliability, one question was asked twice in a reverse direction. Of the total responses, 186 questionnaires did not show consistency between these questions and 21 questionnaires showed the same mark for more than 20 questions in row. Both were considered as having low reliability and were removed from the sample. Thus, after deleting 207 questionnaires (about 10\%), 1887 questionnaires were used for further analysis.

Demographics of respondents were $57.6 \%$ female and $42.4 \%$ male. Among them, $37.9 \%$ were students and $16.5 \%$ were housewives. The average age was 26.8 with a range from 11 to 60 . The average period of participation per member was 4.9 months.

\subsection{Validity and reliability of measure}

Factor analysis with varimax rotation was performed to ascertain the discriminant validity of each construct. Table 3 shows that among the managing strategies, rule and role as well as event and ritual could not be discriminated. Thus, it was decided to reduce the number of managing strategies to four, based upon these results, by merging rule and role into one factor, as well as event and ritual into another.

Table 4 shows that system and information quality could be discriminated except for system quality 4 (Functionality). In prior research (Liu and Arnett, 2000; Kim and Ahn, 1998), this was used for system quality. Thus, it was decided to follow the original construct.

Sense of community resulted in three discriminant factors instead of four. Table 5 shows that emotional connection has no discriminant validity. Two questions of this went to integration and fulfillment of needs and one another went to membership. Prior research has found that sense of community could show the different structure of factors by the types of 
communities or the features of members (Chipuer and Pretty, 1999; Chavis and Pretty, 1999). Thus, based upon the result of factor analysis, sense of community was composed of three distinct factors such as membership, influence, and integration and fulfillment of needs. Meanwhile, visit and participation show high construct validity as shown in Table 6.

In order to ensure that the variables comprising each proposed research construct were internally consistent, reliability assessment was carried out using Cronbach's alpha. As Table 7 shows, all Cronbach's alphas were greater than 0.64 , satisfying a minimum requirement of 0.6 (Van de van and Ferry, 1980).

\subsection{Hypotheses testing}

To avoid being dominated by a single community, we gathered data from eight different communities. However, the numbers of respondents from each community were quite diverse and the recommended sample size for LISREL is around 200. If the sample size greatly exceeds 200, the chi-square statistic can become too sensitive to its sample size difference and overall model fitness can be decreased (Hair et al., 1998). Therefore, we randomly selected 30 cases from each of the eight communities for a total of 240 cases to be analyzed by LISREL.

The LISREL test results are presented in Figure 3, showing the significant paths (p-value $<.05)$ in solid lines. The goodness of fit was 0.98 and the normed fit index was 0.96 . The root mean square residual was 0.033 . These fitness indices show that the model quite well explains the relationships between variables.

Among the null hypotheses regarding managing strategy, hypotheses 1 and 2 were rejected. The LISREL results showed that managing strategy has a positive influence on visit $(\gamma=0.18)$ and sense of community $(\gamma=0.39)$, while it has no influence on participation. The visit was positively influenced by IS quality $(\gamma=0.26)$. Thus hypothesis 4 was rejected. Moreover, visit was positively related with sense of community $(\beta=0.32)$ and sense of community was positively related with participation $(\beta=0.53)$. Thus, hypotheses 5 and 6 were also rejected.

\subsection{Further analysis}

Since there were some discussion about the relationship between sense of community and participation, an additional analysis of this path was performed. The positions of sense of community and participation were switched and a LISREL analysis was performed while keeping other relationships constant. The fitness of the LISREL result (Ratio: $9.43=$ chisquire 28.30/degree of freedom 3, GFI: 0.96, RMR: 0.062, NFI: 0.90) was lower than the fitness of our research model. This implies that the current model is superior to the other model that assumes member participation has an influence on members' sense of community. 
Because the result of the hypothesis test cannot show the detailed implication for community manager, a LISREL analysis for the detailed factors of each construct was conducted.. Although overall fitness was marginally acceptable (Ratio: $11.76=$ chi-squire 188.24/degree of freedom 16, GFI: 0.88, RMR: 0.086, NFI: 0.78), it was deemed sufficient to proceed to show the detailed relationships. As in Figure 4, among the three constructs of sense of community only membership $(\beta=0.52)$ had an influence on participation. Membership was influenced by purpose $(\gamma=0.16)$, subgroups $(\gamma=0.13)$, and visit $(\beta=0.20)$. Meanwhile, subgroups $(\gamma=0.18)$ and information quality $(\gamma=0.31)$ had an influence on visit.

\section{Discussion and conclusions}

\subsection{Discussion of findings}

This research examined all the possible paths leading to participation in a virtual community with two independent variables and two mediating variables. The results show the three following findings.

First, participation could not be enhanced directly. It was revealed that there was no significant direct path from managing strategy to participation. However, the path from sense of community to participation was strongly supported by the results. This then implies that a community manager has to consolidate the sense of community, with membership in particular, in order to enhance participation.

Second, sense of community could be enhanced by an appropriate managing strategy. The path from managing strategy to sense of community has a higher estimate than the estimate of path from visit to sense of community. This implies that appropriate managing strategy could enhance the sense of community without a high number of visits. If a community is managed in the way that the members want, they can feel a sense of community directly without visiting that community that many times. The detailed model shows that membership, a dominant factor of participation, is influenced by purpose and subgroups. However, the path from visit to sense of community should not be ignored.

Third, the number of visits could be increased by the information quality. More than with any other factor, the information quality had the highest influence on the number of visits. This implies that the visits of most members are determined by its information quality. The community, having high information quality, would enjoy more visits than other communities. If a community manager wants to increase members' visits, they have to control information quality.

\subsection{Limitations}

The primary limitation of this research is that each relationship is observed at a certain 
point of time. This might ignore the possibility that one member's sense of community could evolve into participation during a certain period with interactions of a SYSOP or other members. In addition, a member's visit could be increased as a result of member participation. Thus, a longitudinal study that observes members' evolvement from low involvement to high involvement may be required to overcome this limitation.

Another limitation is that this research focused only on the B-to-C communities, and the results cannot be generalized for B-to-B or other types of B-to-C communities. It is true that there are many different types of communities in Internet. Each community might have a different type of path leading to participation or a different managing strategy that is most appropriate. To resolve this question, research that shows the difference between community's categories should be conducted. 


\section{References}

Bachrach, Kenneth, and Zautra A. "Coping with a Community Stressor: The Threat of Hazardous Waste Facility," Journal of Health and Social Behavior (26:2), 1985, pp 127141.

Brodsky, Anne E., O'Campo, Patricia J. and Aronson, Robert E. "PSOC in community context: multi-level correlate of a measure of psychological sense of community in lowincome, urban neighborhoods," Journal of Community Psychology (27:6), 1999, pp. 659679.

Chavis, David M. and Pretty, Grace M.H. "Sense of Community: Advances in measurement and application," Journal of Community Psychology (27: 6), 1999, pp. 635642.

Chavis, David M., Hogge, James H., McMillan, David W., and Wandersman, Abraham "Sense of community through Brunswik's Lens: A first look," Journal of Community Psychology (14:1), 1986, pp. 24-40.

Chavis, David M. and Wandersman, Abraham "Sense of community in the Urban Environment: A Catalyst for Participation in Community Development," American Journal of Community Psychology (18:1), 1990, pp. 55-81.

Chipuer, Heather M. and Pretty, Grace M.H. "A review of the sense of community index: current uses, factor structure, reliability, and further development," Journal of Community Psychology (27: 6), 1999, pp. 643-658.

Cothrel, Joseph "Measuring the Success of an Online Community," Strategy and Leadership (28:3), 2000, http://www.participate.com/research/art-measuresuccess.asp.

Davis, F.D. "A Technology Acceptance Model for Empirically Testing New End-User Information Systems: Theory and Results," Doctoral Dissertation, Sloan School of Management, Massachusetts Institutes of Technology, 1986.

DeLone, W. H. and McLean, E. R. "Information Systems Success: The Quest for the Dependent Variable," Information Systems Research (3:1), 1992, pp. 60-95.

Hagel III, John and Armstrong, Arthur, Net Gain, Harvard Business School Press, 1997.

Hair, Joseph F., Anderson, Rolph E., Tatham, Ronald L. and Black, William C., Multivariate Data Analysis, Prentice Hall, 1998.

Heller, Ken "The Return to Community," American Journal of Community Psychology (17:1), 1989, pp. 1-15

Julian, David A., Reischl, Thomas M., Carrick, Richard V., and Katrenich, Cathy "Citizen Participation - Lessons from a Local United Way Planning Process," Journal of the American Planning Association (64:3), 1997, pp. 345-355.

Kim, Amy Jo, Community Building on the Web, Peachpit Press, 2000.

Kim, Joon S., and Ahn, Joon-Mo "Information System's Impact on Organization's Performance: research framework and field research," Yonsei University YISRI working paper, 1998.

Kozinets, Robert V. "E-Tribalized Marketing: The Strategic Implication of Virtual Communities of Consumption," European Management Journal (17:3), 1999, pp. 252-264.

Liu, Chang and Arnett, Kirk P. "Exploring the factors associated with Web site success in the context of electronic commerce," Information \& Management (38), 2000, pp. 23-33. 
Martin, Chuck, Net Future, McGraw-Hill, 1999.

McMillan, David W. and Chavis, David M. "Sense of Community: A Definition and Theory”, Journal of Community Psychology (14:1), 1986, pp. 6-23.

McWilliam, Gil "Building stronger brands through online communities", Sloan Management Review (41:3), 2000, pp. 43-55.

Meehan, Emily "Using Online Community as a Crucial Market Intelligence Resource," Internet Market Strategies (6:13), 2000, pp 1-12.

Park, Hee-Sung, Lee, Moon-Bong, and Suh, Kil Soo "The effect of Sense of Virtual Community on Customer Loyalty in the Electronic Market Place," Proceedings of 1999 Fall Korea Management Information System Conference, 1999, pp 185-194.

Park, Ki-Woo, Choi, Soon-Hwa, and Lee, Sang-Min "The Valuation of Cyber Community," Samsung Economic Research Institute Digital Symposium, 2000, pp. 359-388.

Pretty, Grace M.H. and McCarthy, Mary "Exploring Psychological Sense of Community among Women and Men of the Corporation," Journal of Community Psychology (19:3), 1991, pp. 351-361.

Reichheld, Frederick F. and Schefter, Phil "E-Loyalty: Your Secret Weapon on the Web", Harvard Business Review (79:4), 2000, pp. 105-113.

Rheingold, H. "A slice of life in my Virtual Community", http://www.communities. com /paper/ settlmnt.html, 1992.

Sculley, Arthur B. and Woods, William A, B2B Exchange: the killer application in the business-to-business internet revolution, ISI publication, 1999.

Seddon, P. B. "A Respectation and Extension of the DeLone and McLean Model of IS Success," Information Systems Research (8:3), 1997, pp. 240-253.

Williams, Ruth L. and Cothrel, Joseph "Four smart ways to run online communities", Sloan Management Review (41:4), 2000, pp. 81-91.

Ven de Van, A. H. and Ferry, D. L. Measuring and Assessing Organization, WileyInterscience, New York, 1980.

Zimmerman, Mark A., and Julian Rappaport "Citizen Participation, Perceived Control, and Psychological Empowerment," American Journal of Community Psychology (16:5), 1988, pp 725-750. 


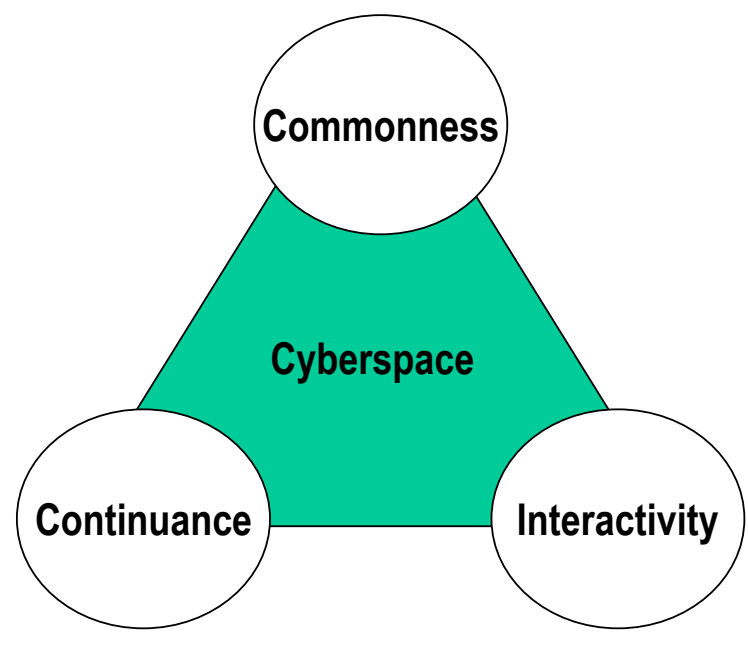

Table 1. Nine design strategies

\begin{tabular}{|c|l|}
\hline Strategy & \multicolumn{1}{c|}{ Details } \\
\hline Purpose & $\begin{array}{l}\text {-Construct a mission statement } \\
\text {-Create a strong site personality }\end{array}$ \\
\hline Places & $\begin{array}{l}\text { - Provide a good system overview } \\
\text { - Include rich communication features }\end{array}$ \\
\hline Profiles & $\begin{array}{l}\text { - Make profile easy and fun } \\
\text {-Keep the profiles up-to-date and evolving }\end{array}$ \\
\hline Roles & $\begin{array}{l}\text {-Offer increased privileges to regulars } \\
\text {-Recruit leaders and mentors from within }\end{array}$ \\
\hline Leadership & $\begin{array}{l}\text {-Set up your program to grow } \\
\text {-Set reasonable expectations for online support }\end{array}$ \\
\hline Rule & $\begin{array}{l}\text {-Create and enforce your code of conduct } \\
\text {-Define an escalation path }\end{array}$ \\
\hline Events & $\begin{array}{l}\text {-Hold regular, hosed themed events } \\
\text {-Conduct community surveys }\end{array}$ \\
\hline Rituals & $\begin{array}{l}\text {-Celebrate events that reinforce social identity } \\
\text {-Acknowledge important personal events }\end{array}$ \\
\hline Subgroups & $\begin{array}{l}\text {-Provide features that facilitate small groups } \\
\text {-Create contests for subgroups }\end{array}$ \\
\hline
\end{tabular}


Table 2. Sense of community and the factors influencing it

\begin{tabular}{|c|l|}
\hline Sense of community & Factors \\
\hline Membership & $\begin{array}{l}\text {-Boundary } \\
\text {-Common symbol system: dress, ritual, language }\end{array}$ \\
\hline \multirow{2}{*}{ Influence } & $\begin{array}{l}\text {-Cohesiveness, conformity and consensual } \\
\text { validation } \\
\text {-Understanding of community's needs and } \\
\text { leadership }\end{array}$ \\
\hline Integration and & -Person and environment fit \\
fulfillment of needs & -Effective reinforcement by rewarding contributors \\
\hline Emotional & -Number of contact and quality of interaction \\
connection & -Opportunity of shared worthwhile event \\
\hline
\end{tabular}

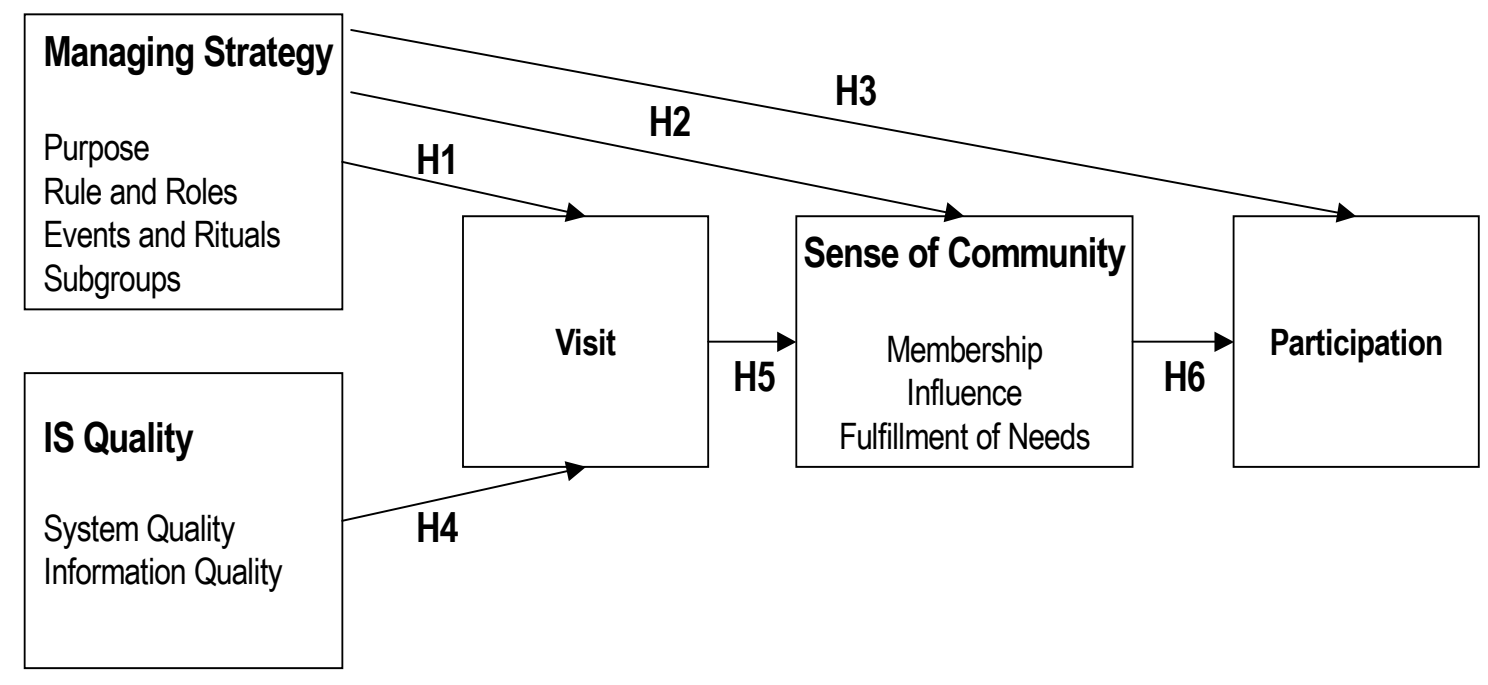

Figure 2. Research model

Table 3. Factor analysis of managing strategy

\begin{tabular}{c|cccc}
\hline & \multicolumn{4}{|c}{ Component } \\
\hline Rule1 & 1 & 2 & 3 & 4 \\
Rule2 & .837 & & & \\
Role2 & .708 & & .244 & \\
Role1 & .571 & .201 & & \\
Ritual1 & .523 & & .239 & .354 \\
Event2 & & .809 & & \\
Ritual2 & .267 & .715 & .226 & \\
Event1 & .616 & & .205 \\
Purpose2 & .342 & .444 & .226 & \\
Purpose1 & & & .905 & \\
Subgroup1 & & & .905 & \\
Subgroup2 & & & & .873 \\
\hline
\end{tabular}


Table 4. Factor analysis of IS quality

\begin{tabular}{l|cc}
\hline & \multicolumn{2}{|c}{ Component } \\
\hline & 1 & 2 \\
Information Quality 5 & .799 & \\
Information Quality 1 & .788 & \\
Information Quality 4 & .756 & \\
Information Quality 2 & .754 & \\
Information Quality 3 & .736 & .218 \\
System Quality 4 & .610 & .361 \\
System Quality 1 & & .784 \\
System Quality 2 & & .729 \\
System Quality 3 & .298 & .696 \\
System Quality 5 & .326 & .653 \\
\hline
\end{tabular}

Table 5. Factor analysis of sense of community

\begin{tabular}{c|ccc}
\hline & \multicolumn{3}{c}{ Component } \\
\hline $\begin{array}{c}\text { Integration and Fulfillment of } \\
\text { Needs 2 }\end{array}$ & .841 & 2 & 3 \\
Integration and Fulfillment of & .785 & .229 & \\
Needs 1 & & & \\
Integration and Fulfillment of & .700 & & \\
$\quad$ Needs 3 & & & \\
Emotional Connection 3 & .564 & .316 & .317 \\
Emotional Connection 1 & .511 & .424 & .366 \\
Membership 1 & & .863 & \\
Membership 2 & .325 & .765 & \\
Emotional Connection 2 & .211 & .653 & .341 \\
Membership 3 & .412 & .606 & .285 \\
$\quad$ Influence 2 & .227 & & .835 \\
Influence 3 & .250 & & .814 \\
Influence 1 & & .425 & .517 \\
\hline
\end{tabular}

Table 6. Factor analysis of visit and participation

\begin{tabular}{c|cc}
\hline & \multicolumn{2}{|c}{ Component } \\
\hline & 1 & 2 \\
Participation 3 & .844 & \\
Participation 4 & .811 & \\
Participation 1 & .750 & \\
Participation 2 & .744 & .243 \\
Visit 1 & & .937 \\
Visit 2 & .250 & .900 \\
\hline
\end{tabular}


Table 7. Cronbach's alpha of all constructs

\begin{tabular}{c|cc}
\hline Construct & $\begin{array}{c}\text { \# of } \\
\text { Questions }\end{array}$ & Cronbach's Alpha \\
\hline Purpose & 2 & 0.8582 \\
Rule & 4 & 0.6675 \\
Event & 4 & 0.6407 \\
Subgroup & 2 & 0.7749 \\
System Quality & 5 & 0.7492 \\
Information Quality & 5 & 0.8521 \\
Visit & 2 & 0.8601 \\
Participation & 4 & 0.8139 \\
Integration and fulfillment of & 5 & 0.8172 \\
needs & 4 & 0.8222 \\
Membership & 3 & 0.6894 \\
Influence & &
\end{tabular}

Figure 3. Path estimates of structural model $(N=240)$

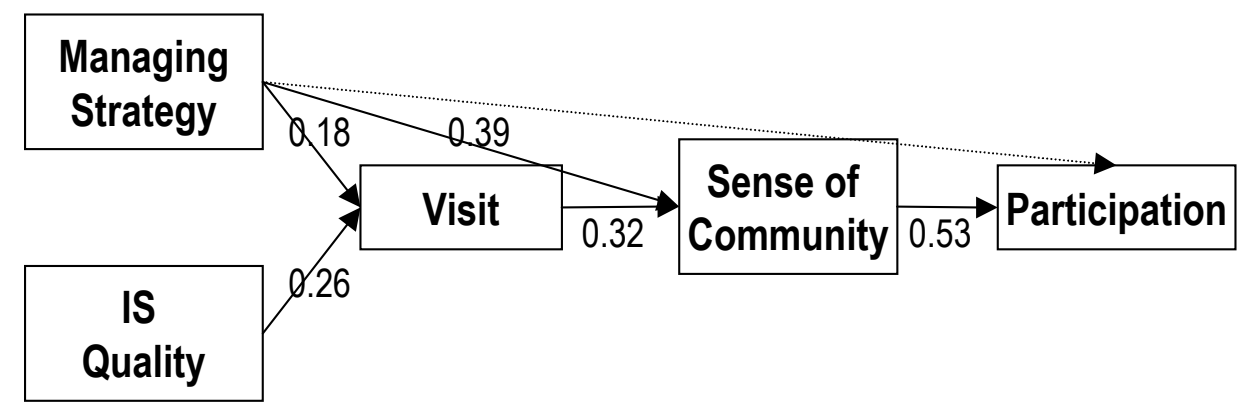

\begin{tabular}{|c|c|}
\hline Fitness & Index \\
\hline $\mathrm{X}^{2}$ (Degree of Freedom: 3 ) & 11.04 \\
\hline Goodness of Fit Index (GFI) & 0.98 \\
\hline Root Mean square Residual (RMR) & 0.033 \\
\hline Normed Fit Index (NFI) & 0.96 \\
\hline
\end{tabular}


Figure 4. Path estimates of detailed structural model $(N=240)$

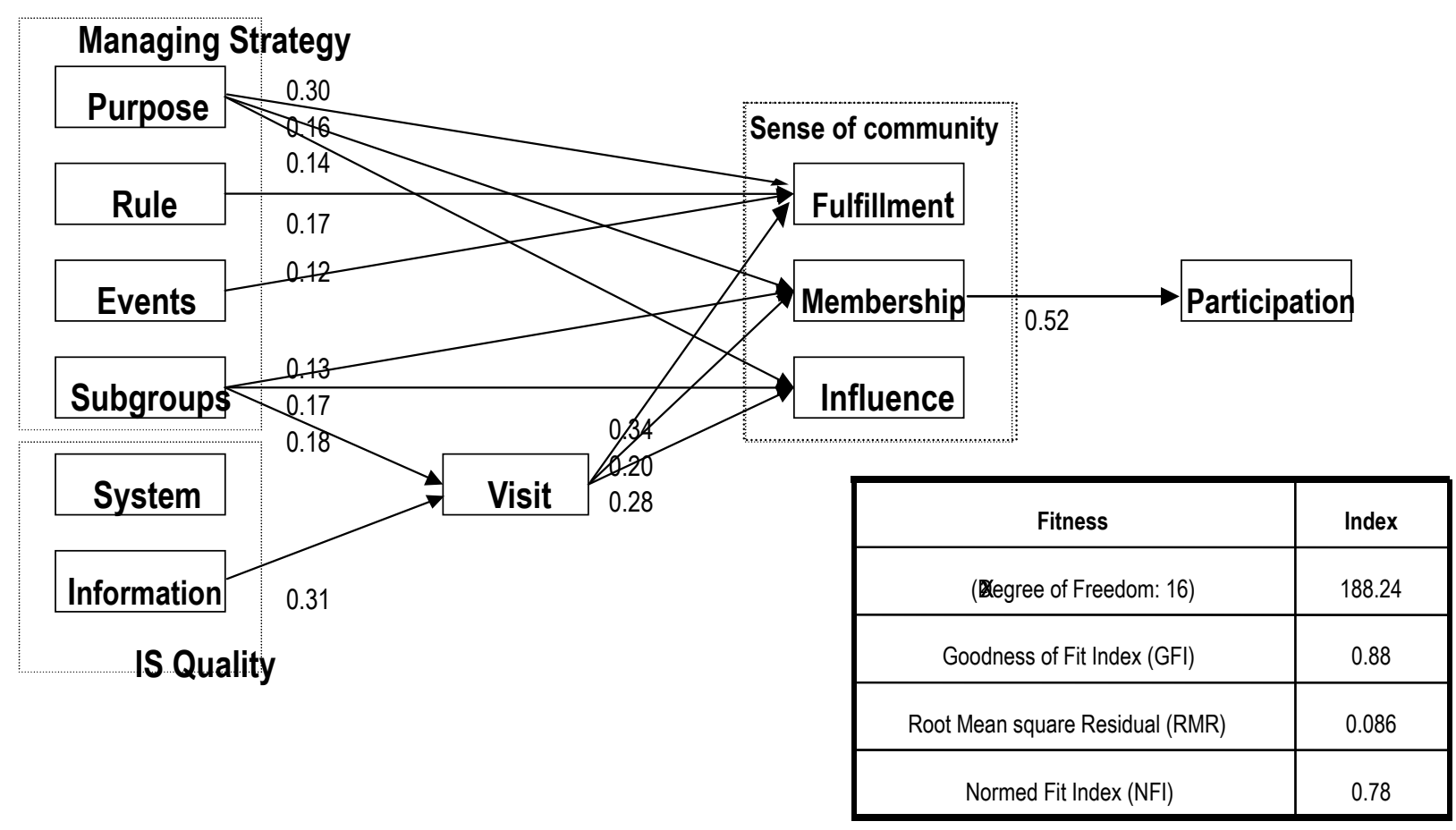

